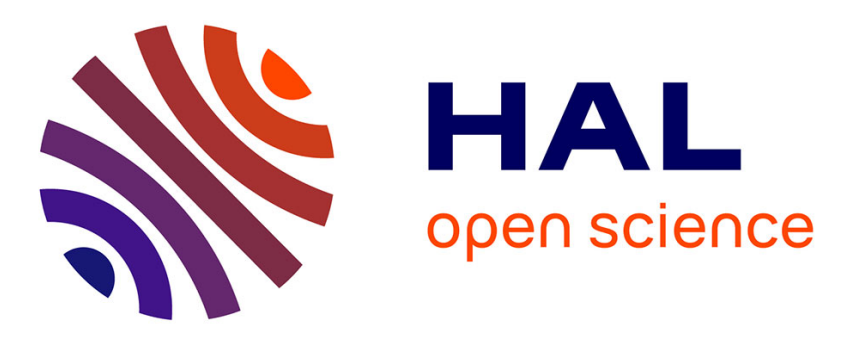

\title{
Thermally Stable Ohmic Contact to p-Type 4H-SiC Based on Ti3SiC2 Phase
}

Tony Abi-Tannous, Maher Soueidan, Gabriel Ferro, Mihai Lazar, Christophe Raynaud, Bruno Gardiola, Dominique Planson

\section{- To cite this version:}

Tony Abi-Tannous, Maher Soueidan, Gabriel Ferro, Mihai Lazar, Christophe Raynaud, et al.. Thermally Stable Ohmic Contact to p-Type 4H-SiC Based on Ti3SiC2 Phase. Materials Science Forum, 2016, 858, pp.553-556. 10.4028/www.scientific.net/MSF.858.553 . hal-01388027

\section{HAL Id: hal-01388027 https://hal.science/hal-01388027}

Submitted on 22 May 2019

HAL is a multi-disciplinary open access archive for the deposit and dissemination of scientific research documents, whether they are published or not. The documents may come from teaching and research institutions in France or abroad, or from public or private research centers.
L'archive ouverte pluridisciplinaire $\mathbf{H A L}$, est destinée au dépôt et à la diffusion de documents scientifiques de niveau recherche, publiés ou non, émanant des établissements d'enseignement et de recherche français ou étrangers, des laboratoires publics ou privés. 


\title{
Thermally stable ohmic contact to $\mathrm{p}$-type $4 \mathrm{H}-\mathrm{SiC}$ based on $\mathrm{Ti}_{3} \mathrm{SiC}_{2}$ phase
}

\author{
T. Abi-Tannous ${ }^{1, a *}$, M. Soueidan ${ }^{1, b}$, G. Ferro ${ }^{2, c}$, M. Lazar ${ }^{1, d}$, C. Raynaud ${ }^{1, e}$ \\ B. Gardiola ${ }^{2, f^{\prime}}$ and D. Planson ${ }^{1, g}$
}

${ }^{1}$ Université de Lyon, CNRS, Laboratoire Ampère, INSA-Lyon, UMR 5005, F-69621, France

${ }^{2}$ Université de Lyon, CNRS, Laboratoire des Multimatériaux et Interfaces, UMR 5615, F-69622, France

atony.abi-tannous@insa-lyon.fr, ${ }^{b}$ maher.soueidan@insa-lyon.fr, 'gabriel.ferro@univ-lyon1.fr, dmihai.lazar@insa-lyon.fr, echristophe.raynaud@insa-lyon.fr, 'bruno.gardiola@univ-lyon1.fr, ${ }^{9}$ dominique.planson@insa-lyon.fr

Keywords: Ti-Al ohmic-contacts, $\mathrm{Ti}_{3} \mathrm{SiC}_{2}$, p-type $4 \mathrm{H}-\mathrm{SiC}$, TFE

\begin{abstract}
In this study, the electrical properties of $\mathrm{Ti}_{3} \mathrm{SiC}_{2}$ based ohmic contacts formed on p-type $4 \mathrm{H}-\mathrm{SiC}(0001) 4^{\circ}$-off substrates were studied. $\mathrm{The} \mathrm{Ti}_{3} \mathrm{SiC}_{2}$ thin films were grown by thermal annealing (from $900^{\circ} \mathrm{C}$ to $1200^{\circ} \mathrm{C}$ ) of $\mathrm{Ti}_{50} \mathrm{Al}_{50}$ layer deposited by magnetron sputtering. XRD analyzes were performed on the samples to further investigate the compounds formed after annealing. Using TLM structures, the Specific Contact Resistance (SCR) at room temperature of all contacts was measured. The temperature dependence (up to $600^{\circ} \mathrm{C}$ ) of the SCR was studied to understand the current mechanisms at the interface and to determine the barrier height value by fitting the experimental results using the thermionic field emission theory. Aging tests showed that $\mathrm{Ti}_{3} \mathrm{SiC}_{2}$ based contacts were stable up to $200 \mathrm{~h}$ at $600^{\circ} \mathrm{C}$ under $\mathrm{Ar}$.
\end{abstract}

\section{Introduction}

The high-temperature functionality of $\mathrm{SiC}$ devices is useless without ohmic contacts that are also capable of operation under the same conditions. However, during long-term operation at high temperatures, reactions between metal and $\mathrm{SiC}$ can continue to evolve, thus leading to an alteration of the interface properties. The aim of this work is to realize an ohmic contact on p-type $\mathrm{SiC}$ that is as stable as possible after high temperature ageing.

P-Type 4H-SiC has a high work function (around 6-7 eV) and it does not exist any conventional metal that leads to low Schottky barrier height when deposited on P-Type 4H-SiC [1]. Such contacts are generally employed containing aluminium [2], and a great deal of attention has been focused on Al-Ti [3]. Toward this aim, Titanium Silicon Carbide $\left(\mathrm{Ti}_{3} \mathrm{SiC}_{2}\right)$ is one of the best candidate materials, because this carbide has a very interesting combination of metallic and ceramic properties, together with an excellent chemical stability with $\mathrm{SiC}_{\mathrm{C}} \mathrm{Ti}_{3} \mathrm{SiC}_{2}$ can be obtained by annealing of $\mathrm{Ti} / \mathrm{SiC}[4]$ or $\mathrm{Ti}-\mathrm{Al} / \mathrm{SiC}[3]$.

This paper reports on the electrical characterization of $\mathrm{Ti}_{3} \mathrm{SiC}_{2}$ ohmic contact to p-type $4 \mathrm{H}-\mathrm{SiC}$. We study the effect of Ti-Al annealing temperature for the formation of ohmic contact. Finally, the behaviours of the ohmic contact at very high temperature (up to $600^{\circ} \mathrm{C}$ ) and after $200 \mathrm{~h}$ of aging are discussed.

\section{Experimental section}

P-type epilayers $\left(\sim 1.3 \mu \mathrm{m}\right.$ thick) doped with $\mathrm{Al}$ in the $[1-4] \times 10^{19} \mathrm{~cm}^{-3}$ range on $4 \mathrm{H}-\mathrm{SiC}(0001)$ $4^{\circ}$ off substrates were used. The samples were chemically cleaned to remove any surface pollution. This implied acetone and ethanol ultrasonic degreasing for $5 \mathrm{~min}$ each, followed by two times $\mathrm{H}_{2} \mathrm{SO}_{4}: \mathrm{H}_{2} \mathrm{O}_{2}(2: 1)$ for 10 minutes and finally $\mathrm{HF}$ acid diluted at $5 \%$ for $4 \mathrm{~min}$, before rinsing with deionized water. Then, mesa structures were formed by reactive ion etching (RIE) for isolating the p-layer. After RIE, the samples underwent a second chemical cleaning as mentioned above, which was followed by the deposition of $200 \mathrm{~nm} \mathrm{Ti}_{50} \mathrm{Al}_{50}$ stacking by magnetron sputtering from $\mathrm{Ti}_{50} \mathrm{Al}_{50}$ target in a high vacuum system. The deposition was carried out at room temperature with RF plasma formed at an Ar constant pressure of $5 \times 10^{-3}$ mbar. 
After metal deposition, Transfer Length Method (TLM) structures were fabricated on the mesa in order to characterize electrically the metal/SiC p-type contact. The geometric patterns for the TLM measurements were obtained through a photolithographic procedure. The unwanted metal was removed by wet etching using commercial Al-etch solution at $60^{\circ} \mathrm{C}$. The TLM contact consists of seven rectangular electrodes $(500 \mu \mathrm{m} \times 100 \mu \mathrm{m})$ with increasing spacing of $3,6,10,20,40,80$ and $120 \mu \mathrm{m}$. For ohmic contact formation, high temperature annealing was performed in a Rapid Thermal Annealing (RTA) furnace under argon at atmospheric pressure with advanced backing steps ( 3 times pumping followed by argon filling) before the annealing in order to decrease the residual oxygen concentration in the RTA chamber [5]. After a heating rate of $20^{\circ} \mathrm{C} / \mathrm{s}$ the annealing temperature of the $10 \mathrm{~min}$ plateau was varied from 900 to $1200^{\circ} \mathrm{C}$.

\section{Samples characterizations}

Fig. 1-a shows X-ray diffraction (XRD) $\theta-2 \theta$ scan of typical samples annealed at $900,1000,1100$ and $1200^{\circ} \mathrm{C}$. As seen, the diffraction peaks unambiguously reveal the formation of the hexagonal $\mathrm{Ti}_{3} \mathrm{SiC}_{2}$ structure which is in epitaxial relation with the substrate. Transmission Electron Microscopy characterization (not shown here) shows that the $4 \mathrm{H}-\mathrm{SiC}$ substrate is entirely covered by a $\mathrm{Ti}_{3} \mathrm{SiC}_{2}$ layer, which is itself covered by an Al-riche layer (mixture of pure $\mathrm{Al}$ and $\mathrm{Al}_{3} \mathrm{Ti}$ ) [5]. The current-voltage (I-V) characteristics measured between two adjacent TLM pads (Fig. 1-b) shows a non-ohmic behavior on as-prepared samples and on samples annealed at $900^{\circ} \mathrm{C}$. But for the samples annealed at $1000^{\circ} \mathrm{C}$ or above, I-V behaviors are linear and prove that the contact is ohmic. Fig. 1-c shows the Specific Contact Resistance (SCR) $\rho_{\mathrm{c}}$ extracted from TLM measurements from those contacts that displayed ohmic characteristics. As seen, the SCR increases with annealing temperature. The $\mathrm{Ti}_{50} \mathrm{Al}_{50}$ annealed at $1000^{\circ} \mathrm{C}$ yielded the lowest SCR of $1.1 \times 10^{-4} \Omega . \mathrm{cm}^{2}$, and hence this sample was selected for further electrical measurements at high temperature, between $300 \mathrm{~K}$ and $875 \mathrm{~K}$.

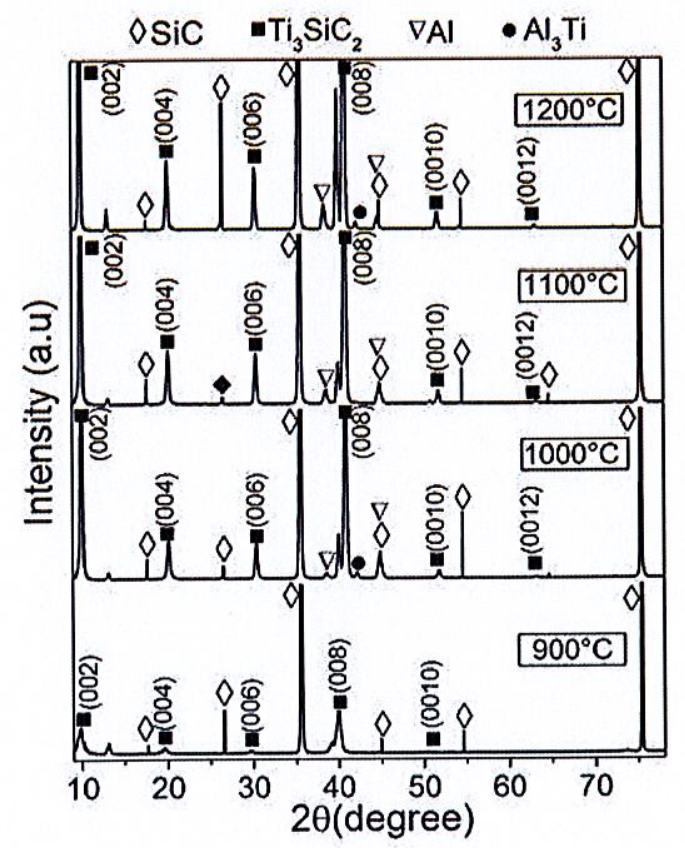

(a)
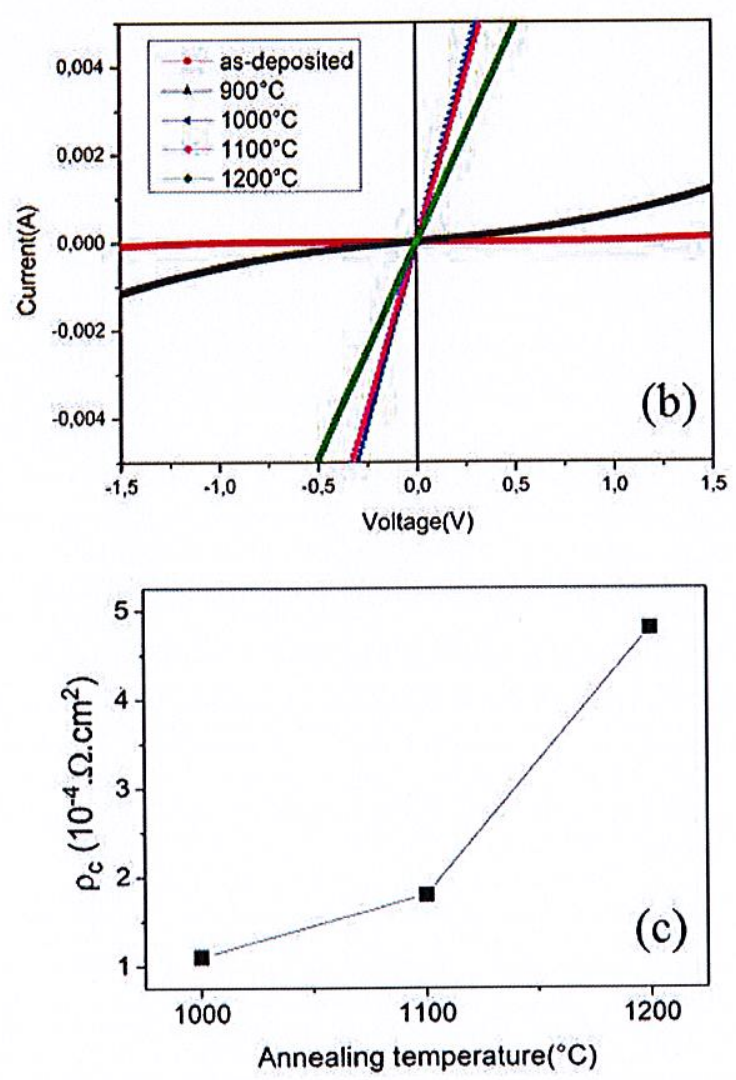

Fig. 1: (a) XRD patterns of the $\mathrm{Ti}_{50} \mathrm{Al}_{50}$ contacts onto $4 \mathrm{H}-\mathrm{SiC}$ (0001), after annealing at different temperatures, (b) I-V characteristics measured between 2 adjacent pads as-deposited and after annealing at different temperatures, (c) Evolution of the SCR with the annealing temperature. 
From the temperature dependence of the TLM measurements performed on $1000^{\circ} \mathrm{C}$ annealed sample, the evolution of the sheet resistance $\left(\mathrm{R}_{\mathrm{sh}}\right)$ of the p-layer (Fig. 2) and of the SCR (Fig. 3) were extracted as a function of the measurement temperature. Both $R_{\mathrm{sh}}$ and SCR were found to decrease with increasing measurement temperature, respectively from $\sim 2 \mathrm{k} \Omega / \mathrm{sq}$ to $0.2 \mathrm{k} \Omega / \mathrm{sq}$ and from $1.1 \times 10^{-4}$ to $9.8 \times 10^{-6} \Omega . \mathrm{cm}^{2}$.

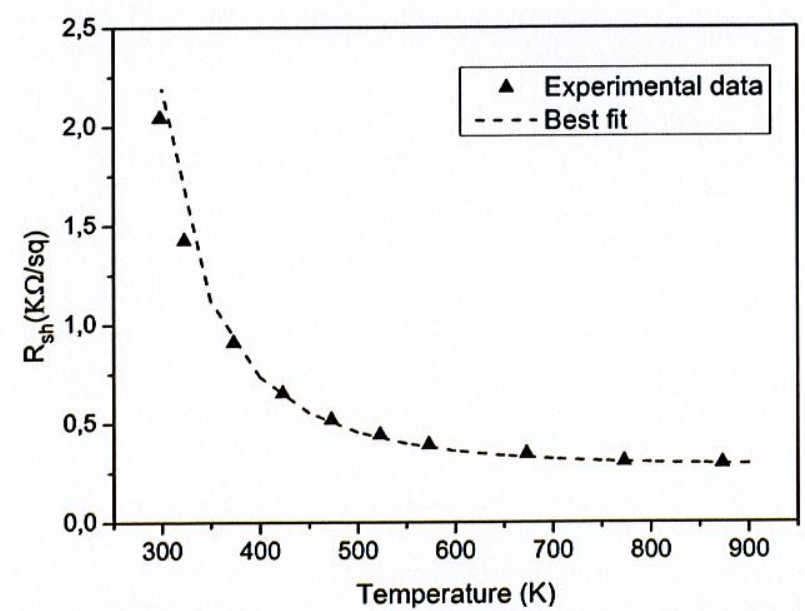

Fig. 2: Temperature dependence of the $R_{\text {sh }}$ of the p-layer for the sample annealed at $1000^{\circ} \mathrm{C}$.

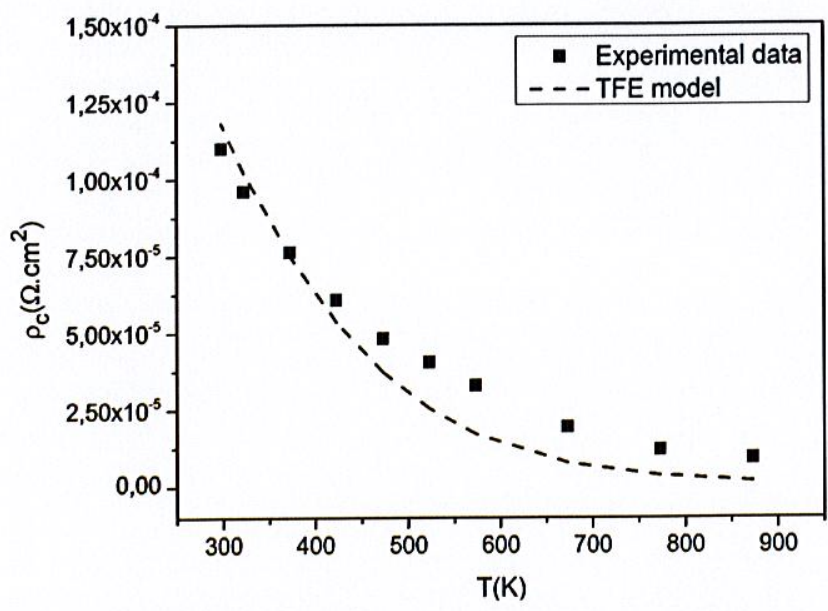

Fig. 3: Temperature dependence of the SCR for the sample annealed at $1000^{\circ} \mathrm{C}$.

To determine exactly the doping concentration $\mathrm{N}_{\mathrm{A}}$ of the p-layer, the $\mathrm{R}_{\mathrm{sh}}$ experimental data, reported in Fig. 2, were fitted using the expression of the sheet resistance defined by:

$$
R_{s h}(T)=\frac{1}{q \mu_{p}(T) p(T) e}
$$

where "q" is the elementary charge; " $\mu_{\mathrm{p}}(\mathrm{T})$ " is the holes mobility, "p(T)" is the free hole concentration and "e" is the thickness of the p-layer (in our case e $\sim 1.3 \mu \mathrm{m}$ ).

The temperature dependence of the holes mobility $\mu_{\mathrm{p}}(\mathrm{T})$ and the free hole concentration $\mathrm{p}(\mathrm{T})$ is given by the following relations :

$\mu_{p}(T)=\mu_{p}(300)\left(\frac{T}{300}\right)^{-\beta}$

$$
\frac{p(T) \times\left(p(T)+N_{D}\right)-n_{i}^{2}}{N_{A}-N_{D}-p(T)+n_{i}^{2} / p}=\frac{N_{V}}{g} \exp \left(-\frac{E_{A}}{k T}\right)
$$

where " $\beta$ " is an empirical parameter depending on the doping concentration $\mathrm{N}_{\mathrm{A}}$, " $\mu_{\mathrm{p}}(300)$ " the hole mobility at $300 \mathrm{~K}$, " $\mathrm{k}$ " the Boltzmann constant, " $\mathrm{N}_{\mathrm{D}}$ " the concentration of compensating donors, " $\mathrm{n}_{\mathrm{i}}$ " the intrinsic carrier density, " $\mathrm{N}_{\mathrm{V}}$ " the effective density of states in the valence band, "g" the degeneracy factor for acceptors and " $E_{\mathrm{A}}$ " the ionization energy of acceptors referred to the top of the valence band. This ionization energy is given by [6]:

$$
E_{A}(e V)=0.265-3.6 \times 10^{-8}\left(1-\frac{N_{D}}{N_{A}}\right)^{1 / 3} N_{A}^{1 / 3}
$$

Where $\left(\mathrm{N}_{\mathrm{D}} / \mathrm{N}_{\mathrm{A}}\right)$ is the compensation ratio.

In these calculations, the doping concentration $\mathrm{N}_{\mathrm{A}}$ and the compensation ratio $\left(\mathrm{N}_{\mathrm{D}} / \mathrm{N}_{\mathrm{A}}\right)$ were considered as fitting parameters. From the best fit in Fig. 2, we found $\mathrm{N}_{\mathrm{A}}=3 \times 10^{19} \mathrm{~cm}^{-3}$ (with $3 \%$ compensation). This value of $\mathrm{N}_{\mathrm{A}}$ was used to determine the Schottky barrier height $\left(\phi_{\mathrm{B}}\right)$ of the contact from the fitting of the SCR experimental data (Fig. 3) using the TFE model. In this model, the SCR can be expressed as [7]:

$$
\rho_{c}=\frac{1}{q A^{*}} \times \frac{k^{2}}{\sqrt{\pi\left(\phi_{B}+V_{p}\right) E_{00}}} \times \cosh \left(\frac{E_{00}}{k T}\right) \times\left[\sqrt{\operatorname{coth}\left(\frac{E_{00}}{k T}\right)}\right] \times \exp \left(\frac{\phi_{B}+V_{p}}{E_{0}}-\frac{V_{p}}{k T}\right)
$$

where:

$$
E_{00}=\frac{q h}{4 \pi}\left(\frac{N_{A}}{m^{*} \varepsilon}\right)^{\frac{1}{2}}
$$

$$
E_{0}=E_{00} \operatorname{coth}\left(\frac{E_{00}}{k T}\right)
$$


and where " $h$ " is Planck's constant, " $m *$ " the effective mass of the tunneling hole, " $\varepsilon$ " the dielectric permittivity (in the case of $\mathrm{SiC}, \varepsilon=9.7 \varepsilon_{0}, \varepsilon_{0}$ being the vacuum permittivity), $\mathrm{A}^{*}$ the Richardson constant (in the case of $\mathrm{SiC}, \mathrm{A}^{*}=146 \mathrm{Acm}^{-2} \mathrm{~K}^{-1}$ ) and $\mathrm{V}_{\mathrm{p}}$ is the energy difference between the valence-band and the Fermi level.

In these calculations, $\phi_{\mathrm{B}}$ was considered as fitting parameter. The extracted value of $\phi_{\mathrm{B}}$ from curve in Fig. 3 is found to be $0.85 \mathrm{eV}$.

Aging tests on this sample were performed at a constant temperature of $600^{\circ} \mathrm{C}$ in an $\mathrm{Ar}$ atmosphere. The contact resistivity was monitored before and after the tests. In fixed time intervals ( $24,48,100$ and 200 hours), the contacts were cooled down to room temperature, and the contact resistivity was measured. After $100 \mathrm{~h}$ of ageing, the SCR was found to evolve in a positive way by a decrease below $1 \times 10^{-4} \Omega . \mathrm{cm}^{2}$ and the value kept rather constant up to $200 \mathrm{~h}$, which is the maximum ageing time of this study. This evolution suggests that there may be a slight modification (if any) of the $\mathrm{Ti}_{3} \mathrm{SiC}_{2} / \mathrm{SiC}$ interface but this modification is not detrimental to the contact. As a consequence, we believe that $\mathrm{Ti}_{3} \mathrm{SiC}_{2}$ can be considered as a reliable high temperature ohmic contact on $\mathrm{SiC}$.

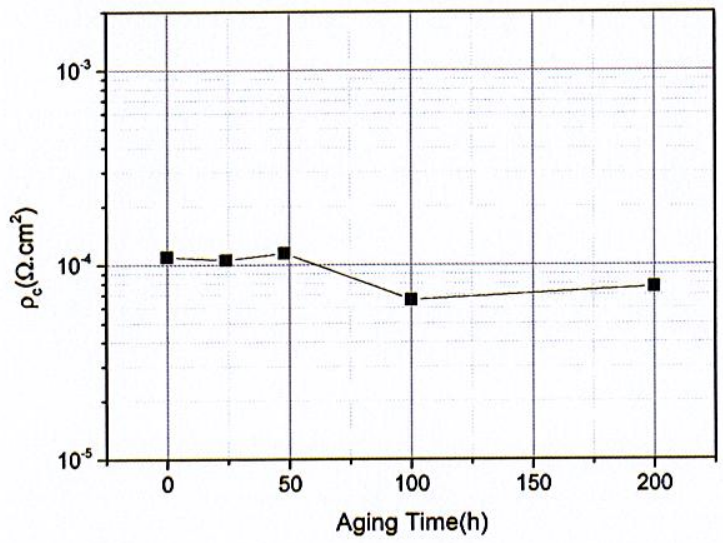

Fig. 4: SCR after aging test of the sample annealed at $1000^{\circ} \mathrm{C}$.

\section{Summary}

We formed epitaxial $\mathrm{Ti}_{3} \mathrm{SiC}_{2}$ onto $4 \mathrm{H}-\mathrm{SiC}(0001) 4^{\circ}$-off from $200 \mathrm{~nm}$ of $\mathrm{Ti}_{50} \mathrm{Al}_{50}$ alloy, deposited by sputtering and annealed in a rapid thermal annealing. According to the TLM measurements, the sample annealed at $1000^{\circ} \mathrm{C}$ resulted in the lowest SCR $\left(1.1 \times 10^{-4} \Omega . \mathrm{cm}^{2}\right)$ and hence was selected for the high temperature characterizations. The temperature dependence of the SCR indicated that thermionic field emission is the dominant transport mechanism and the extracted values of $\phi_{\mathrm{B}}$ from TFE model is $0.85 \mathrm{eV}$. Finally, to investigate the thermal stability of $\mathrm{Ti}_{3} \mathrm{SiC}_{2}$ contact, aging tests done at $600^{\circ} \mathrm{C}$ up to $200 \mathrm{~h}$ led to SCR decrease which is very promising for high temperature use of bipolar $\mathrm{SiC}$ with ohmic contacts on p-type epilayers.

\section{References}

[1] F. Roccaforte, A. Frazzetto, G. Greco, F. Giannazzo, P. Fiorenza, R. Lo Nigro, M. Saggio, M. Leszczynski, P. Pristawko, V. Raineri, Appl. Surf. Sci. 258 (2012) 8324-8333.

[2] M. R. Jennings, C. A. Fisher, D. Walker, A. Sanchez, A. Pérez-Tomás, D. P. Hamilton, P. M. Gammon, S. E. Burrows,S. M. Thomas, Y. Sharma, F. Li, and P. A. Mawby, Mater. Sci. Forum, 778-780 (2014) 432-435.

[3] A. Frazzetto, F. Giannazzo, R Lo Nigro, V. Raineri, and F. Roccaforte, J. Appl.Phys. 44 (2011) 255302.

[4] F. La Via, F. Roccaforte, A. Makhtari, V. Raineri, P. Musumeci, and L. Calcagno, Microelectronic Engineering, 60 (2002) 269-282.

[5] T. Abi-Tannous, M. Soueidan, G. Ferro, M. Lazar, B. Toury, M.F. Beaufort, J.F. Barbot, J. Penuelas and D. Planson, Appl. Surf. Sci. 374 (2015) 186-192.

[6] A. Koizumi, N. Iwamoto, S. Onoda, T. Ohshima, T. Kimoto, K. Uchida and S. Nozaki, Mater. Sci. Forum, 679-680 (2011) 201-204.

[7] A.Y.C. Yu, Solid-State Electron. 13 (1970) 239-247. 